\title{
Structure Determination of a Natural Juvenile Hormone Isolated from a Heteropteran Insect
}

\author{
Toyomi Kotaki, ${ }^{1}$ Tetsuro Shinada, ${ }^{2}$ and Hideharu Numata ${ }^{3}$ \\ ${ }^{1}$ Division of Insect Sciences, National Institute of Agrobiological Sciences, Ohwashi, Tsukuba, Ibaraki 305-8634, Japan \\ ${ }^{2}$ Graduate School of Science, Osaka City University, Osaka 558-8585, Japan \\ ${ }^{3}$ Graduate School of Science, Kyoto University, Kyoto 606-8502, Japan
}

Correspondence should be addressed to Toyomi Kotaki, kotaki@affrc.go.jp

Received 15 September 2011; Accepted 7 November 2011

Academic Editor: Mark M. Feldlaufer

Copyright (C) 2012 Toyomi Kotaki et al. This is an open access article distributed under the Creative Commons Attribution License, which permits unrestricted use, distribution, and reproduction in any medium, provided the original work is properly cited.

\begin{abstract}
Juvenile hormone $(\mathrm{JH})$, which occurs in several forms in different insects, is one of the most important insect hormones. The structure of $\mathrm{JH}$ in Heteroptera has not been elucidated until recently, although insects in this suborder have long been used as experimental animals for $\mathrm{JH}$ research. Here we review the structure determination of a novel JH in a stink bug, Plautia stali, which was named juvenile hormone III skipped bisepoxide [ $\mathrm{JHSB}_{3}$ : methyl $(2 R, 3 S, 10 R)-2,3 ; 10,11$-bisepoxyfarnesoate], based on the arrangement of two epoxides at C2,3 and C10,11 with a skipped double bond at C6,7.
\end{abstract}

\section{Introduction}

Juvenile hormone $(\mathrm{JH})$ is an important regulator of many functions in all insects (Figure 1) [1, 2]. It controls various aspects of development including metamorphosis, reproduction, and polyphenism. This hormone was discovered in a blood-sucking bug, Rhodnius prolixus, by Wigglesworth in 1934 [3]. He demonstrated a hormone, produced by a gland behind the brain, the corpus allatum (CA), that was responsible for the maintenance of juvenile characters as the insect grew, hence the name juvenile hormone [3]. $\mathrm{He}$ also found that the gland became inactive to allow metamorphosis to the adult and active again in the adult to support reproductive functions such as deposition of yolk in eggs and production of secretions of accessory reproductive glands $[4,5]$. Since the chemical structure of JH isolated from a moth, Hyalophora cecropia, was elucidated in 1967 [6], several forms of JH were also determined $[1,2]$. JH III is the most common among various insect orders while JH 0 , JH I, $\mathrm{JH}$ II, and 4-methyl JH I were found in Lepidoptera. $\mathrm{JHB}_{3}$ was identified as a JH specific to higher Diptera (Cyclorrhapha) $[1,2]$. However, the structure of $\mathrm{JH}$ in the suborder Heteroptera has remained uncertain in spite of attempts to identify it [7-13]. Recently, we identified the structure of JH in a stink bug, Plautia stali, and named it juvenile hormone III skipped bisepoxide ( $\left.\mathrm{JHSB}_{3}\right)$ and demonstrated its biological function as the $\mathrm{JH}$ in this stink bug [14, 15]. Here we review the process of structure determination of $\mathrm{JHSB}_{3}$ and its biological function as $\mathrm{JH}$ in $P$. stali.

\section{Heteropteran Insects in JH Research}

In his pioneering work, Wigglesworth found a humoral factor controlling metamorphosis and reproduction in $R$. prolixus, which he first referred to as "inhibitory hormone" $[3,5]$ and later as JH [16]. Since then heteropterans have been employed for evaluation of the biological efficacy of synthetic derivatives of natural $\mathrm{JHs}$ and anti-JH compounds, which lead to the discovery of a JH analogue specific to Pyrrhocoris apterus, juvabione and anti-JH, precocenes [17-20].

Heteropteran insects are used for studies to elucidate the role of $\mathrm{JH}$ in various aspects of insect development. For example, in Oncopeltus fasciatus, JH was demonstrated to control reproduction, adult diapauses, and diapause-associated migration $[21,22]$. In diapausing adults of $P$. apterus, the activity of CA was inhibited by the brain via nervous connections $[23,24]$. The production of methyl farnesoate [25] and JH III [26] by the CA in vitro was reported in Dysdercus fasciatus, O. fasciatus, and Nezara viridula. 


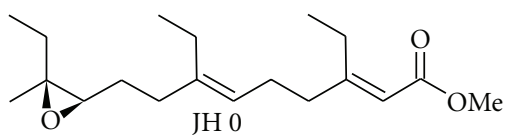<smiles>CC/C(=C\CC/C(C)=C/C(=O)OC)CCC1OC1(C)CC</smiles><smiles>CCC1(C)OC1CC/C(C)=C/CC/C(C)=C/C(=O)OC</smiles><smiles>COC(=O)/C=C(\C)CC/C=C(\C)CCC1OC1(C)C</smiles><smiles>CC/C(=C\CC(C)/C(C)=C/C(=O)OC)CCC1OC1(C)CC</smiles><smiles>COC(=O)/C=C(\C)CCC[C@@](C)([InH2])CCC1OC1(C)C</smiles>

Figure 1: Structure of known JHs.

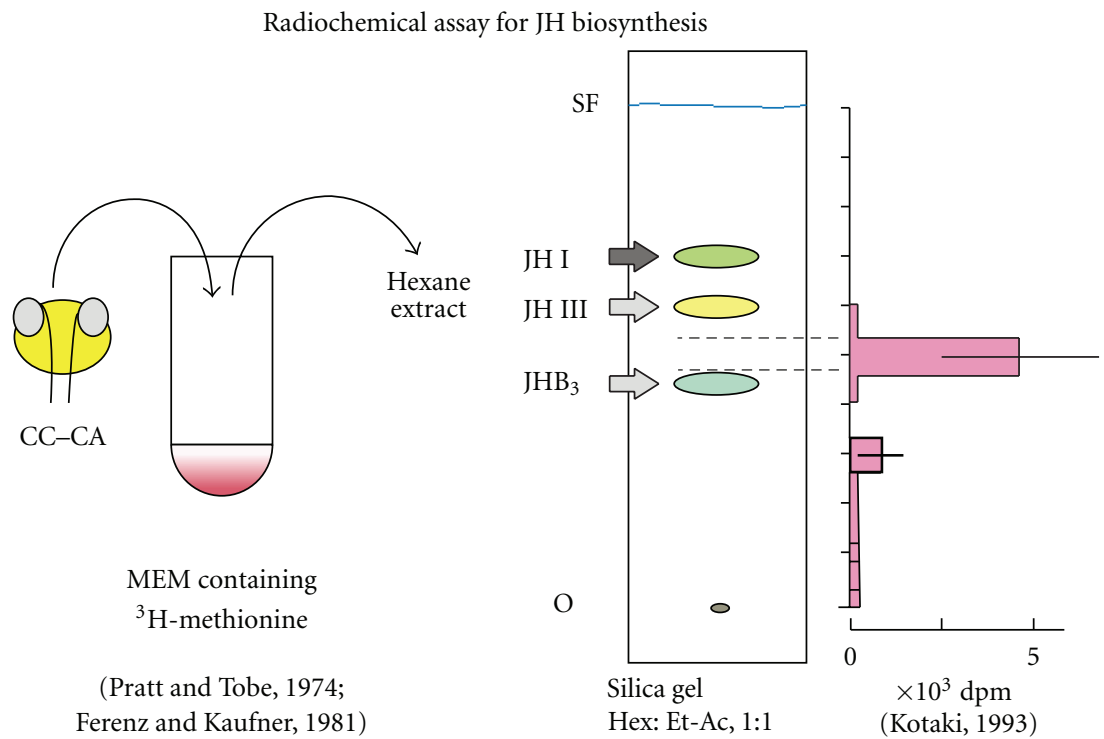

FIGURE 2: Radiochemical assay for JH biosynthesis. Incubation of CA from Plautia stali adults in a medium containing radiolabeled methionine revealed the presence of an unknown product with an $R_{f}$ value different from those of JH I, JH III, or JHB 3 in TLC analysis.

However, Baker et al. failed to detect any form of known JHs in O. fasciatus [12].

\section{Evidence for a New JH in Stink Bugs}

In 1989, we reported that the CA product was responsible for control of adult diapause in P. stali [27]. This was shown by surgical operations such as CA extirpation and implantation. To gain insight into the CA product, the in vitro radiochemical assay $[28,29]$ was adopted to this bug (Figure 2). Assuming that the CA product was a methyl ester as with known JHs, the tritium-labeled CA product would be obtained by the incubation experiments in the presence of $L$ $\left[\right.$ methyl $\left.-{ }^{3} \mathrm{H}\right]$ methionine in the medium. After the incubation period, the product was extracted with hexane and analyzed by thin-layer chromatography (TLC) using a liquid scintillation counter to detect radioactivity of each part of TLC plate. The CA of $P$. stali and three other heteropteran species were subjected to this assay. The $R_{f}$ values for the CA product of four species were almost identical with each other, whereas they were different from those for $\mathrm{JH}$ I, JH III, and $\mathrm{JHB}_{3}[8$, 9]. When precursors of JH III, E,E-farnesol or farnesoic acid were added to the medium, the biosynthesis of CA product was enhanced. This suggested that the product possessed the same sesquiterpenoid skeleton as did JH III [8]. Because radiolabeled JH III added to the incubation medium was not converted to the "CA product," the possibility that the CA released JH III but the latter was degraded or metabolized to the "CA product" in the incubation medium was ruled out [9].

Thus far, at least 7 species from 4 families of Heteroptera seem to share this product $[7,9,10,30]$. Although the CA of $O$. fasciatus, $D$. fasciatus, and $N$. viridula were reported to produce JH III and/or methyl farnesoate in vitro $[25,26]$ and $\mathrm{JH}$ I was found in the hemolymph of $R$. pedestris (formerly $R$. clavatus) [31], the production of JH III and JH I in N. viridula and $R$. pedestris, respectively, was not confirmed [9].

To assess the JH activity of the CA product, we developed a bioassay method using $P$. stali. The CA product, collected as hexane extracts of medium for CA incubation, was topically 


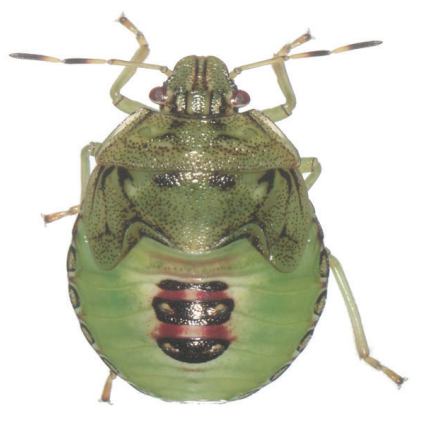

(a)

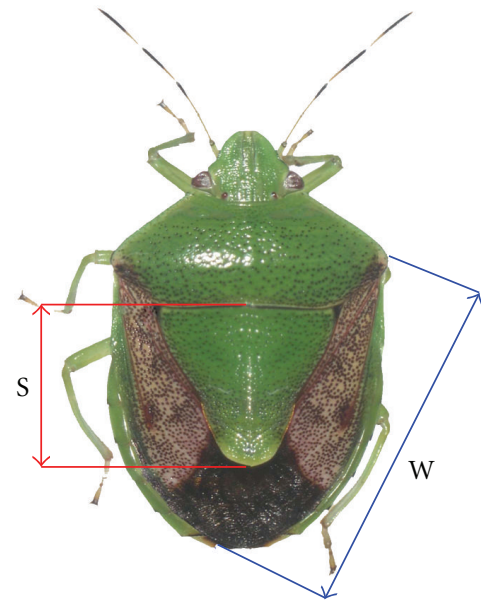

(b)

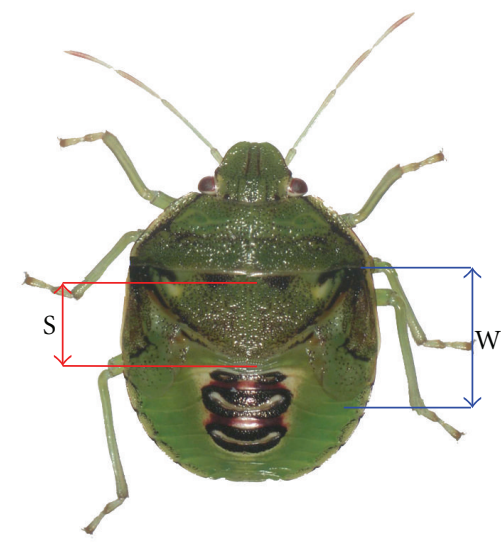

(c)

FIgURe 3: Bioassay for juvenilizing activity in Plautia stali. A last instar nymph (a), an adult (b), and a nymph-adult intermediate (c) obtained as a result of application of JH-active sample. Scale bar: $5 \mathrm{~mm}$. Arrows with labels $\mathrm{W}$ and $\mathrm{S}$ indicate forewing and scutellum lengths and pronotum width, respectively.

applied to last instar nymphs, and following the final ecdysis, relative lengths of forewings and scutellum were determined [8]. Adults have fully developed long forewings and scutellum (Figure 3(b)) while in last instar nymphs and metamorphosis-inhibited insects by $\mathrm{JH}$ application, forewings and scutellum were not developed into the adult form yet but remained in buds or partially developed, short form (Figures 3(a) and 3(c)). The more the CA product was applied to test insects, the shorter their wings and scutellum were. This result indicated that the CA product had the activity to inhibit metamorphosis of the test insects, hence $\mathrm{JH}$ activity. Therefore, $\mathrm{JH}$ in $P$. stali was very likely to be a new $\mathrm{JH}$ that is different from any known $\mathrm{JH}$.

\section{Structure Determination of Stink Bug JH}

To elucidate the structure of stink bug JH, we first examined the molecular weight of CA product using high resolution fast atom bombardment ionization (FAB) mass spectrometry to estimate its compositional formula. The mass of protonated molecule $[\mathrm{M}+\mathrm{H}]^{+}$was estimated to be 283.1885 , leading to a compositional formula, $\mathrm{C}_{16} \mathrm{H}_{26} \mathrm{O}_{4}$, for the CA product. This formula is identical to that for dipteran $\mathrm{JHB}_{3}$. However, previous studies clearly showed that the $R_{f}$ values of the CA product and $\mathrm{JHB}_{3}$ were not the same despite the supposition that the CA product and $\mathrm{JHB}_{3}$ shared a sesquiterpenoid skeleton in common $[8,9]$. Based on these observations, we proposed that the structure of $\mathrm{JH}$ in $P$. stali would be a regio- or geometric isomer of $\mathrm{JHB}_{3}$.

To test this hypothesis, we synthesized a compound mixture consisting of 32 isomers of bisepoxides of methyl farnesoate with $2 E$ or $2 Z$ double bond, epoxides at $\mathrm{C} 2,3$ and at either $\mathrm{C} 6,7$ or $\mathrm{C} 10,11$ by two steps starting from a mixture of $E$ - and $Z$-geranylacetone. The bioassay for $\mathrm{JH}$ activity indicated that the mixture was $\mathrm{JH}$ active. In a GC-MS analysis using a DB-35MS column the mixture gave several peaks. Cochromatography of the mixture and the CA product indicated that one of peaks of the mixture coincided with the CA product in retention time and mass spectrum.

Using a normal phase chiral column, Chiralpak IA (DAICEL Co., Ltd) on an HPLC system, the bisepoxide mixture was separated into 21 fractions and each of them was subjected to the bioassay for JH activity. Two fractions (retention time: $28 \mathrm{~min}$. and $38 \mathrm{~min}$.) applied topically to last instar nymphs showed a juvenilizing effect at a dose of $0.1 \mu \mathrm{g} / \mathrm{insect}$. These biologically active fractions were subjected to one and two-dimensional ${ }^{1} \mathrm{H}$ NMR analyses. Data obtained indicated that each fraction consisted of a single stereoisomer of a novel JH structure, methyl E,E-2,3;10,11-bisepoxyfarnesoate (Figure 4). Although stereoisomers of this bisepoxide had distinctly different retention time when separated by the chiral HPLC, their ${ }^{1} \mathrm{H}$ NMR data were not distinguishable from one another. Probably the positions of two epoxides were too distant to give different signal patterns. Therefore, we synthesized four possible stereoisomers $\mathbf{1 - 4}$ in an optically pure form (Figure 4), and these were compared with the natural $\mathrm{CA}$ product to determine the relative and absolute structure. Each stereoisomer was obtained starting from $E, E-$ farnesol by asymmetric Katsuki-Sharpless epoxidation and Sharpless dihydroxylation reactions in which stereochemical outcomes were reliably controlled by ingeniously designed chiral reagent systems [32]. Bioassay indicated that isomers $\mathbf{1}$ and $\mathbf{2}$ showed more $\mathrm{JH}$ activity than the other two isomers. The chiral HPLC analysis of these stereoisomers gave four peaks. Elution time for isomers $\mathbf{1}$ and $\mathbf{2}$ were almost the same as that for the $\mathrm{JH}$-active fractions obtained by the chiral HPLC separation of the bisepoxide mixture. In consideration of the detection limit of HPLC analysis using a UV detector, the stereoisomers and CA product were subjected to more sensitive GC-MS (chemical ionization, CI with $\mathrm{NH}_{3}$ as 

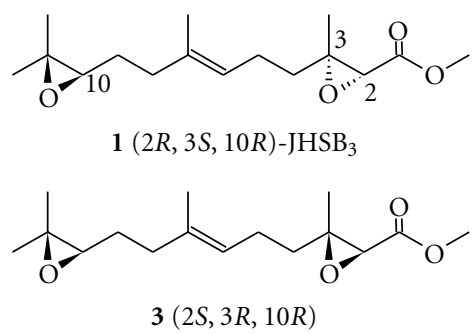

FIGURE 4: Four stereoisomers of $\mathrm{JHSB}_{3}$.

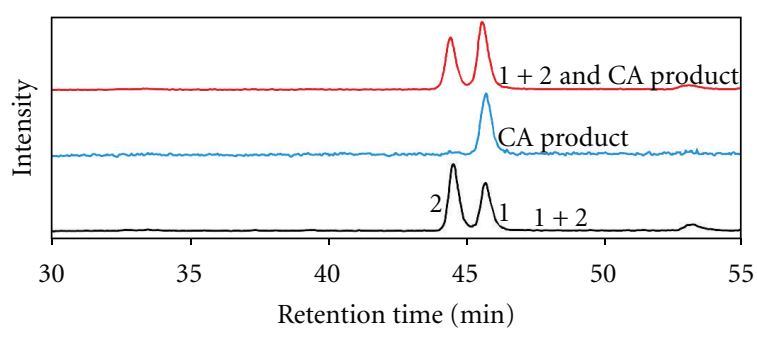

FIgure 5: Chiral GC-MS(CI) analysis of synthetic standards of $\mathrm{JHSB}_{3}(\mathbf{1})$ and isomer 2 and natural product by the CA of Plautia stali using an Rt $\beta$ DEXcst column. Vertical axis indicates signal intensity for $\mathrm{m} / \mathrm{z} 300,\left[\mathrm{M}+\mathrm{NH}_{4}\right]^{+}$. Black, blue, and red lines indicate analysis of $\mathrm{JHSB}_{3}$ (1) and isomer 2 (10 ng each), CA product, and cochromatography of these two samples, respectively [15].

a reagent gas) using a chiral column, Rt- $\beta$ DEXcst. With this column, isomers 2,3 , and 4 showed almost the same retention time of 44.7 min while isomer 1 , with retention time of $45.7 \mathrm{~min}$, was distinctly separated from the others (Figure 5). The CA product produced one main peak at $45.8 \mathrm{~min}$ in this system. The mass spectra for isomer 1 and CA product were identical (Figure 6 insets). Cochromatography of isomer 1 and CA product indicated that the peaks for these two overlapped completely with an increase in peak height in an additive fashion (Figure 5). These results demonstrate that isomer 1, a novel form of $\mathrm{JH}$, is the natural $\mathrm{JH}$ in $P$. stali. We named it juvenile hormone III skipped bisepoxide $\left[\mathrm{JHSB}_{3}\right.$ : methyl $(2 R, 3 S, 10 R)-2,3 ; 10,11$-bisepoxyfarnesoate], based on the arrangement of two epoxides at $\mathrm{C} 2,3$ and $\mathrm{C} 10,11$ with a skipped double bond at C6,7.

\section{Biological Function of $\mathrm{JHSB}_{3}$}

Although, in the process of $\mathrm{JHSB}_{3}$ structure determination, a juvenilizing $\mathrm{JH}$ activity was indicated in $\mathrm{JHSB}_{3}$ and one of its stereoisomers, how active the remaining two stereoisomers at higher doses were was not explored. JH activity of the four isomers were, therefore, compared using last instar nymphs as well as adult females of $P$. stali kept under reproductionpromoting, long-day conditions whose CA were surgically removed. The latter test examined the activity to stimulate reproduction, another function of $\mathrm{JH}$.

Topical application of $\mathrm{JHSB}_{3}$ to last instar nymphs inhibited their metamorphosis in a dose-dependent fashion (Figure 7). Nymphs treated with $0.001 \mu \mathrm{g}$ of $\mathrm{JHSB}_{3}$ molted to
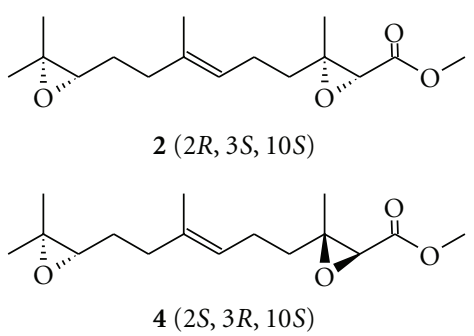

$4(2 S, 3 R, 10 S)$ normal-looking adults. With an increase in the dose, the relative lengths of forewings and scutellum decreased. At a dose of $0.1 \mu \mathrm{g}$ or higher, nymphs molted to intermediates with wings and a scutellum reduced to a similar extent to those of normal last instar nymphs. A diastereomer of $\mathrm{JHSB}_{3}$, isomer 2, revealed a similar dose-response curve. On the other hand, isomers 3 and 4 were less active than $\mathrm{JHSB}_{3}$ and isomer 2. A dose of $1 \mu \mathrm{g}$ of isomers 3 and 4 showed little effect on the metamorphosis of bugs. At a dose of $5 \mu \mathrm{g}$, bugs molted to an intermediate, but their wings and scutellum were still slightly longer than those of bugs treated with $0.1 \mu \mathrm{g}$ or $1 \mu \mathrm{g}$ of $\mathrm{JHSB}_{3}$. Application of $10 \mathrm{R}-\mathrm{JH}$ III showed a similar dose response to those of isomers 3 and $\mathbf{4}$, but even at the highest dose of $10 \mu \mathrm{g}$, its effect was not so evident as that of isomers 3 and 4 at $5 \mu \mathrm{g}$.

Extirpation of the CA from females reared under longday conditions inhibited the development of ovaries. More than half (10 of 14) of allatectomized hexane-treated females underwent oosorption when they were dissected 4 days after allatectomy. Topical application of $\mathrm{JHSB}_{3}$ rescued those adults from the inhibitory effect of CA removal in a dosedependent fashion (Figure 8). Isomer 2 seemed as potent as $\mathrm{JHSB}_{3}$ whereas isomers $\mathbf{3}$ and $\mathbf{4}$ showed virtually no stimulatory effect on oocyte development even at the highest dose of $5 \mu \mathrm{g}$. These results indicated that $\mathrm{JHSB}_{3}$ and isomer 2 were highly $\mathrm{JH}$ active while the other two were about 1,000 times less active. The downward epoxide configuration at $\mathrm{C} 2,3$, shared by $\mathrm{JHSB}_{3}$ and isomer 2 , seems important for manifestation of $\mathrm{JH}$ activity.

$\mathrm{JHSB}_{3}$ structure determination was accomplished by analyzing the product of CA in vitro. The biosynthesis of $\mathrm{JHSB}_{3}$ by the CA, however, does not automatically imply its presence in the hemolymph in vivo. It must be experimentally verified by detecting $\mathrm{JHSB}_{3}$ in the circulating hemolymph. We collected hemolymph samples from reproductively active and diapause females. According to the previous studies [27, 33], in the former the concentration of $\mathrm{JH}$ in the hemolymph is expected to be high while in the latter low. These two samples were analyzed using LC-MS. In the hemolymph sample from reproductively active females, a peak was observed at the same retention time accompanied by the same mass spectrum as synthetic $\mathrm{JHSB}_{3}$ standard. No significant peaks of characteristic fragments corresponding to JH I, II, nor III were observed in the hemolymph samples. This indicated the presence of $\mathrm{JHSB}_{3}$ alone in the hemolymph from reproductively active females, and on the other hand, virtually no peak corresponding to $\mathrm{JHSB}_{3}$ or any other 


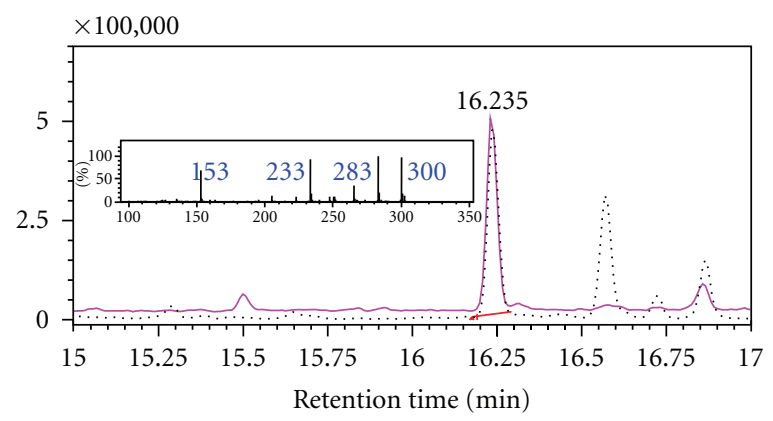

(a)

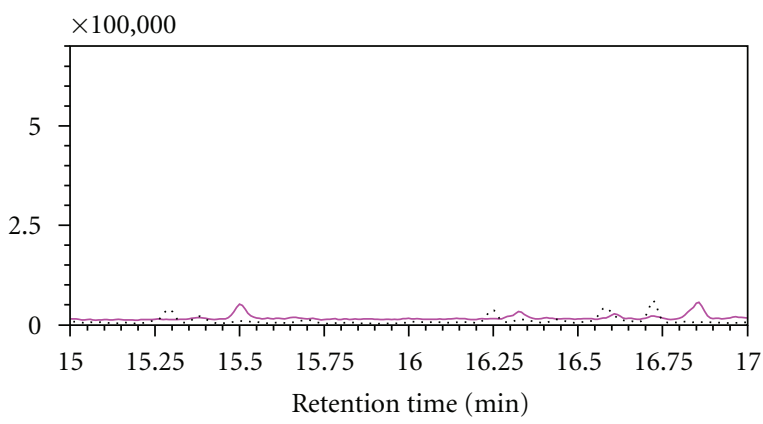

(b)

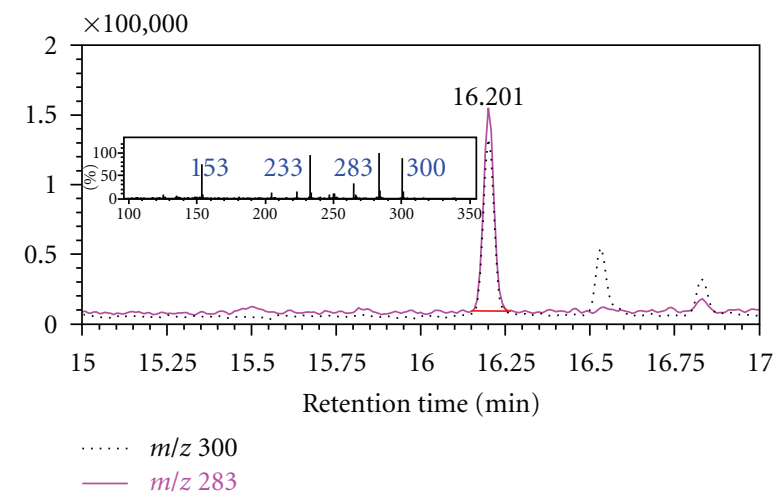

(c)

Figure 6: Detection of $\mathrm{JHSB}_{3}$ (1) from the hemolymph of Plautia stali females. Hemolymph samples collected from reproductively active (a) and diapausing females (b), and $10 \mathrm{ng}$ of synthetic standard of $\mathrm{JHSB}_{3}$ (c) were analyzed on GC-MS using a DB-35MS column. Vertical axis indicates signal intensity for $\mathrm{m} / \mathrm{z} 283,[\mathrm{M}+\mathrm{H}]^{+}$(solid line) and $\mathrm{m} / \mathrm{z} 300,\left[\mathrm{M}+\mathrm{NH}_{4}\right]^{+}$(dotted line). Insets in a and $\mathrm{c}$ indicate a mass spectrum of the peak at $16.2 \mathrm{~min}[14]$.

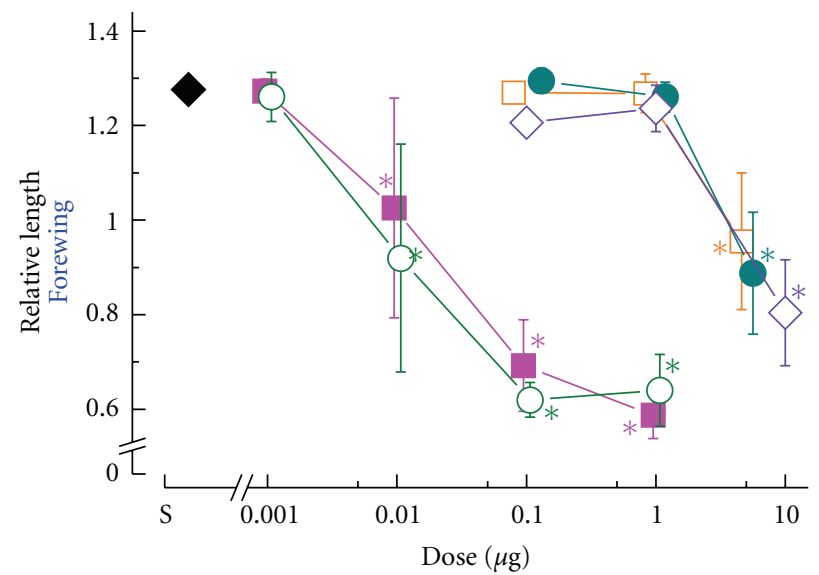

(a)

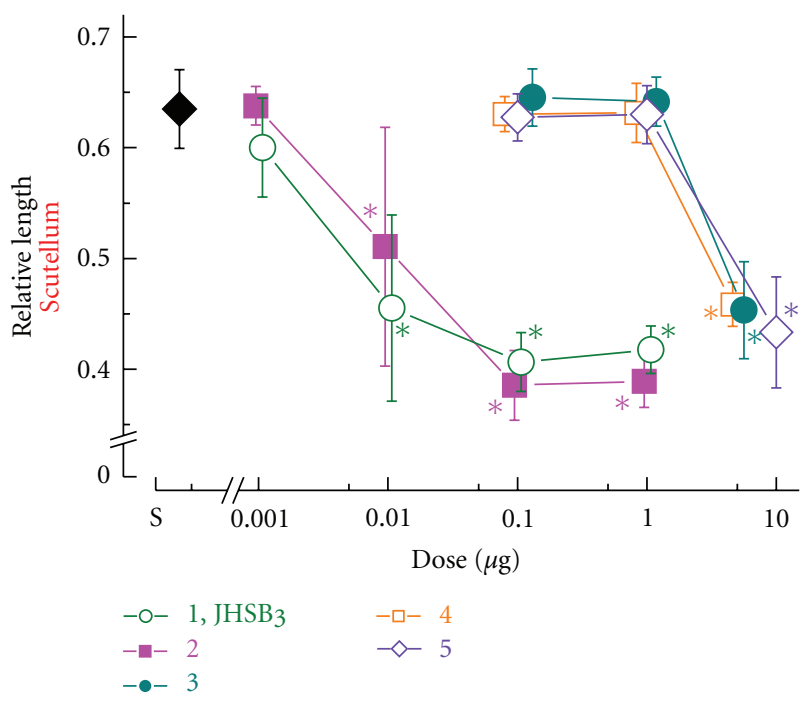

(b)

FIgURE 7: Juvenilizing activity of $\mathrm{JHSB}_{3}(\mathbf{1})$, its stereoisomers and $10 \mathrm{R}-\mathrm{JH}$ III on Plautia stali. Last instar nymphs were treated with a test compound. Following the final molt, lengths of forewing (a) and scutellum (b) relative to the width of pronotum were determined. S on the horizontal axis indicates solvent control. Each datum point and error bar represents average value \pm SD $(n=8-18)$. Asterisks indicate that the average value was significantly different from that of the solvent control (Steel's test, $P<0.05$ ) [14]. 


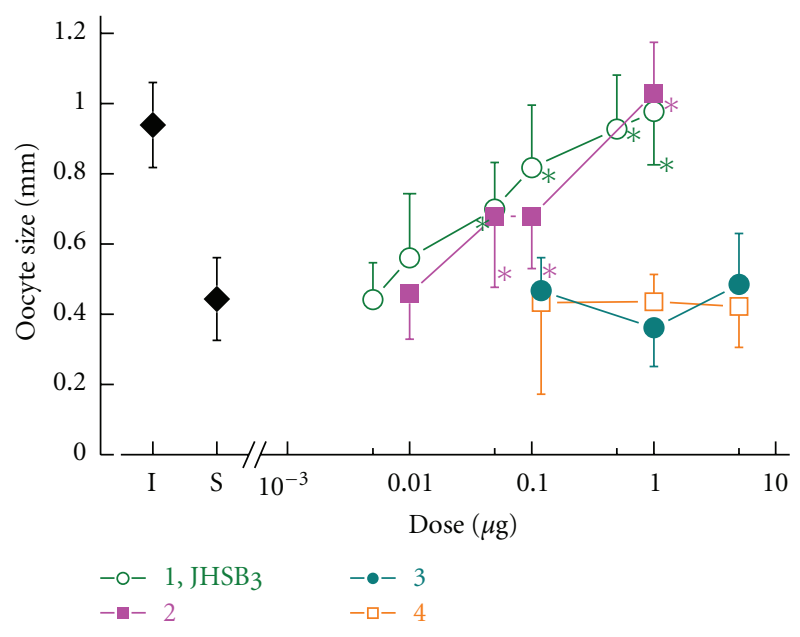

FIGURE 8: Reproduction-stimulating effect of $\mathrm{JHSB}_{3}$ (1) and its stereoisomers on allatectomized females of Plautia stali reared under long-day conditions. Females were allatectomized and treated with a test compound on day 4 of adult life, and oocyte diameter was determined on day 8 . Solid diamonds labeled with I and S on the horizontal axis indicate results of day 8 untreated and solvent-treated adults, respectively. Each datum point and error bar represents average value $\pm \mathrm{SD}(n=8-12)$. Asterisks indicate that the average value was significantly different from that of the solvent control (Steel's test, $P<0.05$ ) [14].

JHs was detected in the sample from diapause females. $\mathrm{JHSB}_{3}$ was, therefore, the only molecule found in the hemolymph and its concentration was likely to fluctuate as expected by the previous studies.

Dahm et al. [34] pointed out three criteria that have to be fulfilled to chemically identify JH. These points, derived from the classical definition of the hormone, are as follows: (1) production by the CA; (2) titer fluctuation in synchrony with the processes controlled by $\mathrm{JH}$; (3) rescue effect in $\mathrm{JH}$ deprived insects. As indicated above, these three criteria were met for $\mathrm{JHSB}_{3}$ in P. stali. $\mathrm{JHSB}_{3}$, therefore, functioned as the $\mathrm{JH}$ in this species. It was likely that other heteropteran insects share this new JH in common because the CA of at least seven heteropterans other than $P$. stali also produced the products in vitro that behaved similarly to that of $P$. stali on the TLC plate $[7,9,10,30]$.

\section{Conclusion}

$\mathrm{JH}$ in Heteroptera has been a long-lasting enigma in spite of that $\mathrm{JH}$ research began with morphological studies in $R$. prolixus $[3,4]$. We have successfully determined the structure of novel, Heteroptera-specific $\mathrm{JH}, \mathrm{JHSB}_{3}$. Because $\mathrm{JHSB}_{3}$ is the only $\mathrm{JH}$ with a $\mathrm{C} 2,3$ epoxide, heteropterans using this molecule likely possess an enzyme responsible for conversion of the C2,3 double bond to epoxide. The presence of specific $\mathrm{JH}$ suggests underlying specific pathways for not only biosynthesis but also degradation. A $\mathrm{JHSB}_{3}$-specific receptor should also play a role in heteropterans. Our discovery has provided a basis for all these suppositions and will enhance further studies on heteropteran JH. An attempt to elucidate the enzymes involved in $\mathrm{JHSB}_{3}$ biosynthesis is in progress. How far $\mathrm{JHSB}_{3}$ is shared among the suborder Heteroptera or the order Hemiptera is a question to be answered in the future in the viewpoint of insect endocrinology and practical insect control, as well. Structure-activity relation study is underway to gain insight into specificity of $\mathrm{JHSB}_{3}$ receptor and development of $\mathrm{JHSB}_{3}$-based control agents.

\section{Acknowledgments}

This study was supported in part by Grants-in-Aid for Scientific Research (C) (no. 19580059) to T. Kotaki and (B) (no. 20380038) to H. Numata from the Japan Society for the Promotion of Science.

\section{References}

[1] E. D. Morgan and I. D. Wilson, "Insect hormones and insect chemical ecology," in Miscellaneous Natural Products Including Marine Natural Products Pheromones Plant Hormones and Aspects of Ecology, K. Mori, Ed., pp. 263-369, Pergamon, Oxford, UK, 1999.

[2] W. G. Goodman and N. A. Granger, "The juvenile hormone," in Comprehensive Molecular Insect Science, L. I. Gilbert, K. Iatrou, and S. S. Gill, Eds., pp. 319-408, Elsevier, Oxford, UK, 2005.

[3] V. B. Wigglesworth, "The physiology of ecdysis in Rhodnius prolixus (Hemiptera). II. Factors controlling moulting and "metamorphosis"', Quarterly Journal of Microscopical Science, vol. 77, no. 2, pp. 191-222, 1934.

[4] V. B. Wigglesworth, "Historical perspectives," in Comprehensive Insect Physiology, Biochemistry and Pharmacology, G. A. Kerkut and L. I. Gilbert, Eds., pp. 1-24, Pergamon, Oxford, UK, 1985.

[5] V. B. Wigglesworth, "The function of the corpus allatum in the growth and reproduction," Quarterly Journal of Microscopical Science, vol. 79, no. 2, pp. 91-120, 1936.

[6] H. Röller, K. H. Dahm, C. C. Sweely, and B. M. Trost, "The structure of juvenile hormone," Angewandte Chemie International Edition, vol. 6, pp. 179-180, 1967.

[7] R. Miyawaki, S. I. Tanaka, and H. Numata, "Role of juvenile hormone in the control of summer diapause in adult Poecilocoris lewisi (Heteroptera: Scutelleridae)," Formosan Entomologist, vol. 26, no. 1, pp. 1-10, 2006.

[8] T. Kotaki, "Evidence for a new juvenile hormone in a stink bug, Plautia stali," Journal of Insect Physiology, vol. 42, no. 3, pp. 279-286, 1996.

[9] T. Kotaki, "Biosynthetic products by heteropteran corpora allata in vitro," Applied Entomology and Zoology, vol. 28, no. 2, pp. 242-245, 1993.

[10] M. Hodková, T. Okuda, and R. Wagner, "Stimulation of corpora allata by extract from neuroendocrine complex; comparison of reproducing and diapausing Pyrrhocoris apterus (Heteroptera: Pyrrhocoridae)," European Journal of Entomology, vol. 93, no. 4, pp. 535-543, 1996.

[11] K. G. Davey, "The modes of action of juvenile hormones: some questions we ought to ask," Insect Biochemistry and Molecular Biology, vol. 30, no. 8-9, pp. 663-669, 2000.

[12] F. C. Baker, L. W. Tsai, C. C. Reuter, and D. A. Schooley, "The absence of significant levels of the known juvenile hormones and related compounds in the milkweed bug, Oncopeltus fasciatus," Insect Biochemistry, vol. 18, no. 5, pp. 453-462, 1988. 
[13] K. Davey, "The interaction of feeding and mating in the hormonal control of egg production in Rhodnius prolixus," Journal of Insect Physiology, vol. 53, no. 3, pp. 208-215, 2007.

[14] T. Kotaki, T. Shinada, K. Kaihara, Y. Ohfune, and H. Numata, "Biological activities of juvenile hormone III skipped bisepoxide in last instar nymphs and adults of a stink bug, Plautia stali," Journal of Insect Physiology, vol. 57, no. 1, pp. 147-152, 2011.

[15] T. Kotaki, T. Shinada, K. Kaihara, Y. Ohfune, and H. N. Mata, "Structure determination of a new juvenile hormone from a Heteropteran insect," Organic Letters, vol. 11, no. 22, pp. 5234 $5237,2009$.

[16] V. B. Wigglesworth, "The determination of characters at metamorphosis in Rhodnius prolixus (Hemiptera)," Journal of Experimental Biology, vol. 17, no. 2, pp. 201-222, 1940.

[17] V. B. Wigglesworth, "The juvenile hormone effect of farnesol and some related compounds: quantitative experiments," Journal of Insect Physiology, vol. 9, no. 1, pp. 105-119, 1963.

[18] G. B. Staal, "Anti-juvenile hormone agents," Annual Review of Entomology, vol. 31, pp. 391-429, 1986.

[19] K. Sláma and C. M. Williams, "Juvenile hormone activity for the bug Pyrrhocoris apterus," Proceedings of the National Academy of Sciences of the United States of America, vol. 54, no. 2, pp. 411-414, 1965.

[20] W. S. Bowers, T. Ohta, J. S. Cleere, and P. A. Marsella, "Discovery of insect anti juvenile hormones in plants," Science, vol. 193, no. 4253, pp. 542-547, 1976.

[21] M. A. Rankin and L. M. Riddiford, "Significance of haemolymph juvenile hormone titer changes in timing of migration and reproduction in adult Oncopeltus fasciatus," Journal of Insect Physiology, vol. 24, no. 1, pp. 31-38, 1978.

[22] M. A. Rankin and L. M. Riddiford, "Hormonal control of migratory flight in Oncopeltus fasciatus: the effects of the corpus cardiacum, corpus allatum, and starvation on migration and reproduction," General and Comparative Endocrinology, vol. 33, no. 3, pp. 309-321, 1977.

[23] M. Hodková, "Function of the neuroendocrine complex in diapausing Pyrrhocoris apterus females," Journal of Insect Physiology, vol. 23, no. 1, pp. 23-28, 1977.

[24] M. Hodková, "Nervous inhibition of corpora allata by photoperiod in Pyrrhocoris apterus," Nature, vol. 263, no. 5577, pp. 521-523, 1976.

[25] M. F. Feldlaufer, W. S. Bowers, D. M. Soderlund, and P. H. Evans, "Biosynthesis of the sesquiterpenoid skeleton of juvenile hormone 3 by Dysdercus fasciatus corpora allata in vitro," Journal of Experimental Zoology, vol. 223, no. 3, pp. 295-298, 1982.

[26] W. S. Bowers, P. A. Marsella, and P. H. Evans, "Identification of an hemipteran juvenile hormone: in vitro biosynthesis of JH III by Dysdercus fasciatus," Journal of Experimental Zoology, vol. 228, no. 3, pp. 555-559, 1983.

[27] T. Kotaki and S. Yagi, "Hormonal control of adult diapause in the brown-winged green bug, Plautia stali Scott (Heteroptera: Pentatomidae)," Applied Entomology and Zoology, vol. 24, no. 1, pp. 42-51, 1989.

[28] G. E. Pratt and S. S. Tobe, "Juvenile hormones radiobiosynthesised by corpora allata of adult female locusts in vitro," Life Sciences, vol. 14, no. 3, pp. 575-586, 1974.

[29] H.-J. Ferenz and I. Kaufner, "Juvenile hormone synthesis in relation to oogenesis in Locausta migratoria," in Juvenile Hormone Biochemistry, G. E. Pratt and G. Brooks, Eds., pp. 135-145, Elsevier, Amsterdam, The Netherlands, 1981.

[30] C. L. Goodman, R. M. Wagner, H. Nabli, M. K. WrightOsment, T. Okuda, and T. A. Coudron, "Partial morphological and functional characterization of the corpus allatum-corpus cardiacum complex from the two-spotted stinkbug, Perillus bioculatus (Hemiptera: Pentatomidae)," In Vitro Cellular and Developmental Biology-Animal, vol. 41, no. 3-4, pp. 71-76, 2005.

[31] H. Numata, A. Numata, C. Takahashi et al., "Juvenile hormone $\mathrm{I}$ is the principal juvenile hormone in a hemipteran insect, Riptortus clavatus," Experientia, vol. 48, no. 6, pp. 606-610, 1992.

[32] K. B. Sharpless, "The search for new chemical reactivity," in Les Prix Nobel. The Nobel Prizes 2001, T. Frängsmyr, Ed., pp. 225-241, Nobel Foundation, Stockholm, Sweden, 2002.

[33] T. Kotaki, "Relationships between JH-biosynthetic activity of the corpora allata in vitro, their size and adult diapause in a stink bug, Plautia crossota stali Scott," Entomological Science, vol. 2, no. 3, pp. 307-313, 1999.

[34] K. H. Dahm, G. Bhaskaran, M. G. Peter, P. D. Shirk, K. R. Seshan, and H. Röller, "On the identity of the juvenile hormone in insects," in The Juvenile Hormone, L. I. Gibert, Ed., pp. 19-47, Plenum, New York, NY, USA, 1976. 

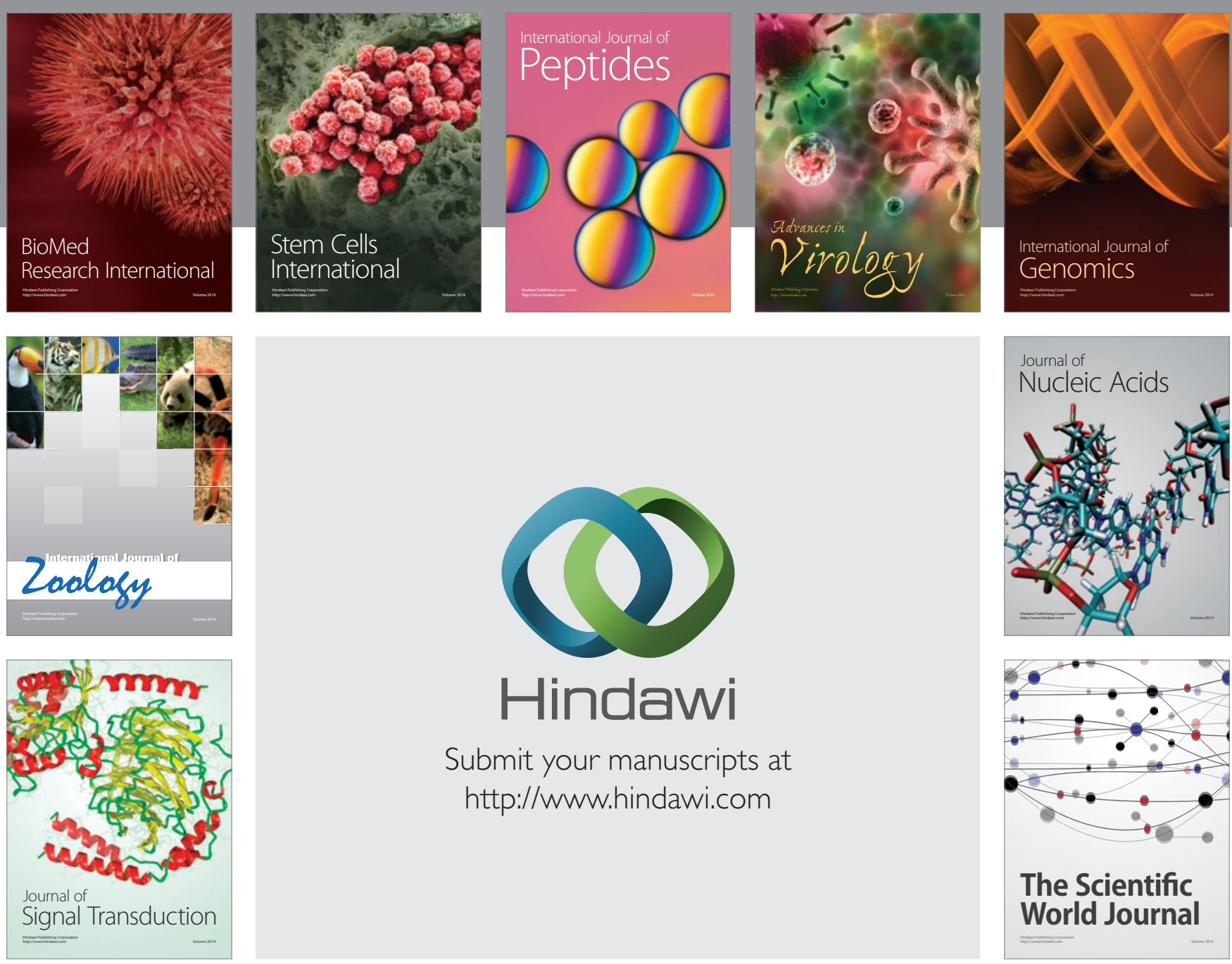

Submit your manuscripts at

http://www.hindawi.com
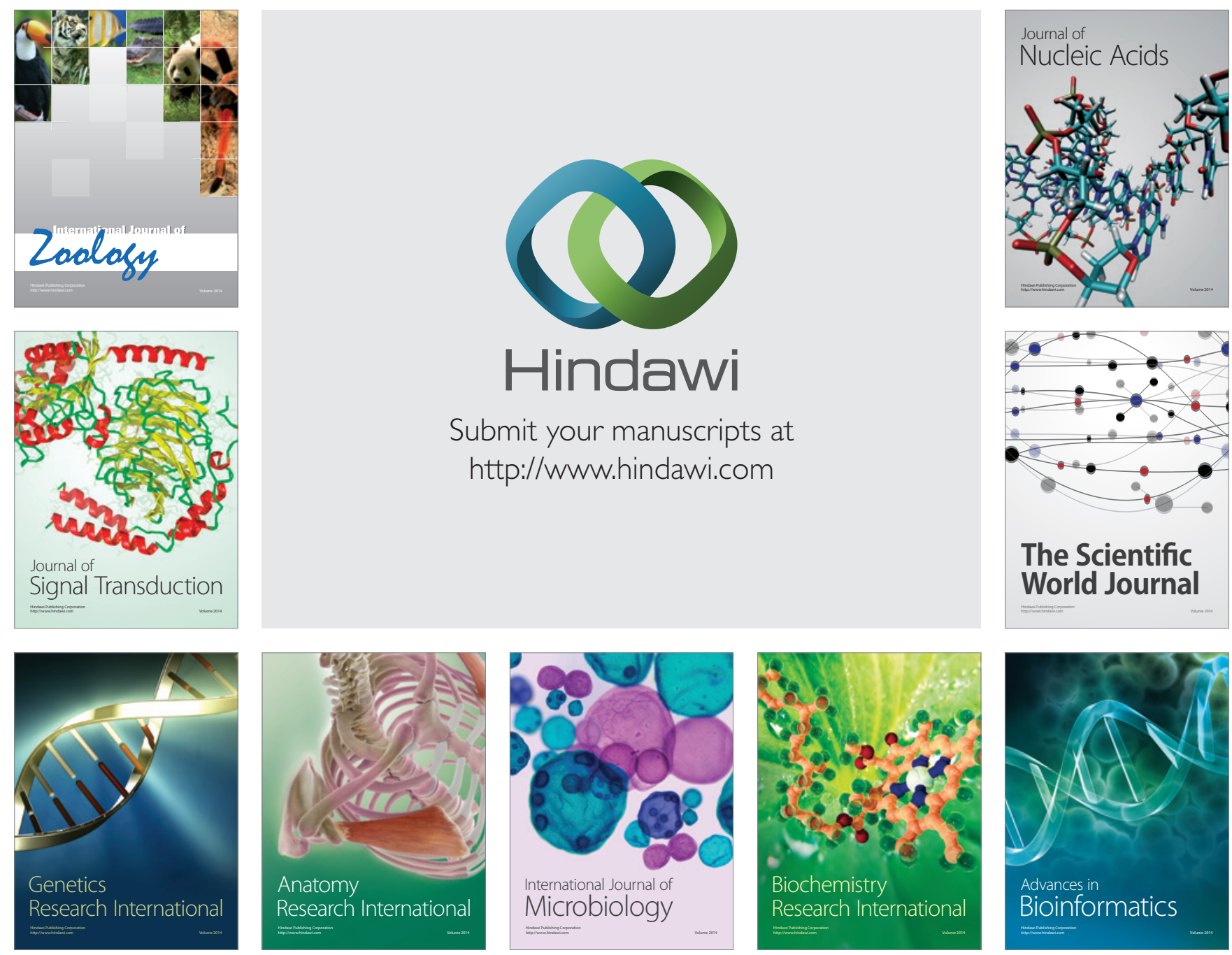

The Scientific World Journal
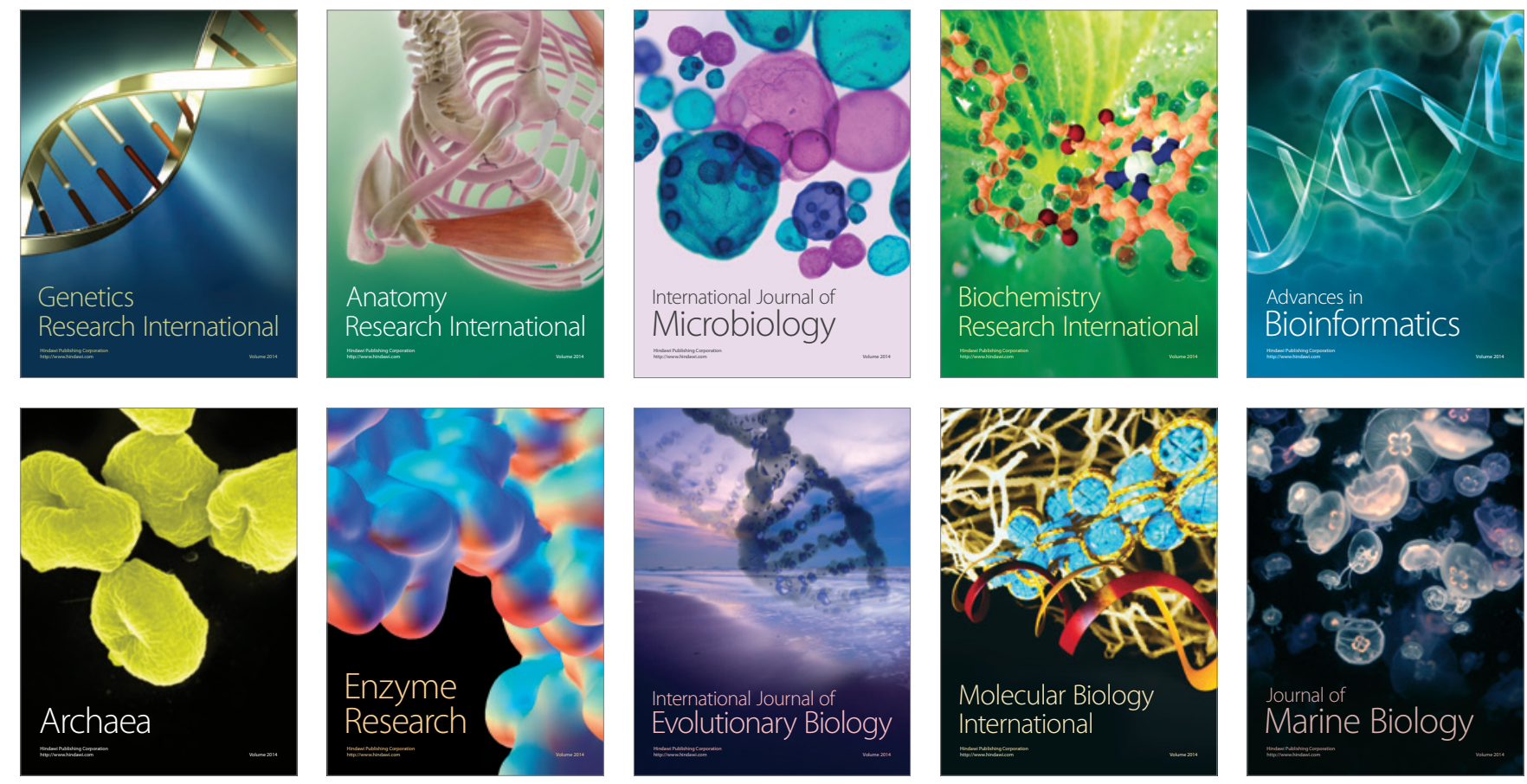